$\begin{array}{ll} & \text { Etnográfica } \\ \text { etnográfica } & \text { Revista do Centro em Rede de Investigação em }\end{array}$ Antropologia

vol. $24(2) \mid 2020$

Vol. $24(2)$

\title{
Introdução: entre a variação e o descontínuo
}

Introduction: between variation and discontinuity

\section{Olívia Maria Gomes da Cunha}

\section{OpenEdition \\ Journals}

\section{Edição electrónica}

URL: https://journals.openedition.org/etnografica/8828

DOI: $10.4000 /$ etnografica.8828

ISSN: 2182-2891

\section{Editora}

Centro em Rede de Investigação em Antropologia

\section{Edição impressa}

Data de publição: 1 junho 2020

Paginação: 341-349

ISSN: 0873-6561

\section{Refêrencia eletrónica}

Olívia Maria Gomes da Cunha, «Introdução: entre a variação e o descontínuo», Etnográfica [Online], vol. 24 (2) | 2020, posto online no dia 31 julho 2020, consultado o 19 janeiro 2022. URL: http:// journals.openedition.org/etnografica/8828 ; DOI: https://doi.org/10.4000/etnografica.8828

\section{(c) (i) (9)}

Etnográfica is licensed under a Creative Commons Attribution-NonCommercial 4.0 International License. 


\section{Introdução:}

\section{entre a variação e o descontínuo}

\section{Olívia Maria Gomes da Cunha}

Esta introdução explora dois temas que orientam a feitura de etnografias sobre as socialidades caribenhas produzidas por autores brasileiros. Ao apresentar os quatro artigos do dossiê dedicados à análise de práticas de confecção e circulação de artefatos materiais e de conhecimento em contextos diversos, a introdução examina os sentidos das noções de variação e da continuidade orientando perspectivas alternativas e possibilidades de diálogo crítico com distintas tradições intelectuais caribenhas e as assim chamadas "antropologias do Caribe".

PALAVRAS-CHAVE: Caribe, antropologia, etnografia, variação, descontinuidade.

Introduction: between variation and discontinuity - This introduction seeks to explore two themes that guide the making of recent ethnographies on the Caribbean socialities. By introducing the four articles of a dossier dedicated to the analysis of material practices, of the creation and the circulation of artifacts of knowledge enmeshed in distinct relations, the introduction examines the effects of the uses of notions such as variation and discontinuity orienting other alternative perspectives of analysis. Their use offers possibilities toward critical dialogues with the Caribbean intellectual traditions, and the so-called the "anthropologies of the Caribbean".

KEYWORDS: Caribbean, anthropology, ethnography, discontinuity, variation.

CUNHA, Olívia Maria Gomes da (omgc@mn.ufrj.br) - programa de pós-graduação em Antropologia Social, Museu Nacional, Universidade Federal do Rio de Janeiro, Brasil. 


\section{OS ARTIGOS QUE COMPÕEM ESTE DOSSIÊ DEBRUÇAM-SE SOBRE} variações e descontinuidades. Trata-se de experimentos etnográficos por meio dos quais os autores procuram ver de perto e descrever, com minúcia e acompanhados da linguagem e dos conceitos criados pelos seus interlocutores, como certas "coisas" são feitas. Tais "coisas" - nesta introdução, ainda acompanhadas de aspas - são diligentemente nomeadas para designar os objetos, os modos de existência e as nem sempre conhecidas relações que eles entretêm, compondo, deste modo, socialidades. Em comum, os artigos descortinam um conjunto de práticas por meio das quais as materialidades, as ontologias e as relações são a base para a produção de novos conhecimentos, instâncias potencialmente criadoras de inovações conceituais, pois as "coisas" criadas resultam de inflexões sobre os modos de os seres e de os objetos existirem, relacionarem-se entre si e de transitarem por entre os mundos nos quais habitam. Ao serem nomeadas e passarem a designar outras (alter) relações - as coisas também desvelam "ontologias invisíveis" (Fields 2001), deixam ver o outrora inefável criando raiz, ganhando forma por meio de engenhos "sociológicos" - nos termos dos interlocutores do batey cubano etnografado por Castro neste dossiê - e outras engenhocas conceituais rizomáticas. Tais "coisas" não designam apenas as relações tensas que têm lugar nos corpos e nos territórios sensíveis nos quais humanos e não humanos circulam. De outro modo, tampouco estão reduzidas aos mecanismos que as cristalizam, fornecendo-lhes carne, forma e limites: as "coisas" não são nem mera objetificação, tampouco inusitadas materialidades sujeitas a recriações simbólicas. Trata-se de atualizações, evidências, índices de presenças (Engelke 2008) e modos de estar no e fazer mundos. Seu fazimento agencia e replica conceitos ao longo de uma miríade de operações e artefatos. A noção de artefato, explorada distintamente por autores como Strathern (1990), Gell (1998), Latour (2005) e Holbraad (2013), entre outros, oferece pistas para observarmos as linhas de força que percorrem os objetos e os seres como relações. Fazer uma "coisa" é criar uma virtualidade, um devir humano, animal, ou artefato aparentemente inerte; implica criar ou tornar visíveis possibilidade de e modo de existência. É sobre inovações - materiais, ontológicas e cosmopolíticas - nas quais artefatos, modos de existência e de conhecimento são mutuamente constituídos, que esses artigos versam.

A variação e o descontínuo revelam-se, por sua, vez, de diferentes maneiras. Nas várias contribuições que integram o dossiê há inúmeras referências a temas "clássicos" explorados nas etnografias do Caribe nas últimas décadas. Se, na relação com a literatura antropológica sobre as socialidades caribenhas, essa relação é de participação, abrindo, por conseguinte, espaço para variações em torno de agendas, temáticas, orientações teóricas e experimentos metodológicos já utilizados, no que concerne ao que se afigura afeito a uma espécie de torção, poderíamos falar em aposta no descontínuo. 
Há, decerto, diferentes modos de tematizar o que chamei variação e as maneiras pelas quais os temas explorados nesse dossiê traçam uma relação de participação com as antropologias do Caribe. À guisa de introdução aos artigos que o compõe, podemos apenas identificar breves inscrições dessas presenças. Ao interrogar o papel da antropologia na feitura de um campo de estudo e epistemologia - os então chamados "estudos caribenhos" ou as "antropologias do Caribe" - Michel-Rolph Trouillot recuperou uma longa tradição crítica acerca dos modos de interrogar e compreender os múltiplos lugares por meio dos quais se pode conhecer o Caribe. Em lugar de textos onde a "região" é continuamente redesenhada como "campo" e espacialidade singular (Trouillot 1983, 1991, 2002, 2016), o autor nos convida a conhecê-la como perspectiva. Para explorar essa vereda, Trouillot oferece um tático desvio de rota. Nem toda a tradição é abandonada, mas apenas aquelas que se ocuparam em tratar a "região" como um território controlado e alter(e)nativo. Outras perspectivas, igualmente "tradições intelectuais", mas produzidas desde e por meio das experiências que perfazem as socialidades caribenhas, são, deste modo, convidadas a adentrar num terreno aparentemente estável, povoado por cartografias e conceitos alheios. Tal opção não implicou optar por interpretações localistas, partidos nativistas. Outras perspectivas alternativas exigiram outro tipo de recuo. Mais do que um território de verificação de conceitos produzidos alhures, as experiências sociais que têm lugar no Caribe compreendido por um "pensamento caribenho" (Meeks e Lindahl 2001; Scott 2013) colocam em xeque tanto os contornos de espaços sociais concebidos a partir da lógica dos Estados-nação, da colonialidade e da expansão do capitalismo, quanto do estatuto das teorias utilizadas para compreendê-los.

É nesse alinhavo entre contextos de produção de um pensamento social crítico que interroga as agendas dos estudos de área que, nas últimas décadas, uma série de intervenções, no campo historiográfico e antropológico, vem revisitando os significados tradicionalmente atribuídos a concepções de fronteira, nação, Estado-nação e transnacionalismo - noções que o pensamento antropológico privilegiou no entendimento de diferentes socialidades caribenhas (Sheller 2003; Thomas 2013; Thomas e Slocum 2008). Ao chamar certas "tradições intelectuais" produzidas no Caribe por autores caribenhos como plataforma, inflexão e intervenções críticas sobre o "Ocidente" ou do "Atlântico Norte" visto do Caribe, Trouillot refaz os contornos de uma antropologia situada e inventa um ponto de vista interessado. O autor ousou ir além, tornando conceitos como "Estado" e "Ocidente" tropos de uma "geografia da imaginação" ocidental. O resultado desse deslocamento do campo de visão é o desvelar da(s) poética(s) e da(s) política(s), agenciadas por sujeitos, simultaneamente, "primitivos" e "modernos". O Caribe como inscrição e perspectiva privilegiada é, por este caminho, muito mais do que um conjunto de territórios insulares e continentais, além-mar de histórias coloniais, experimentos 
de soberania, duplicação, replicação e criação linguísticas e políticas. É um artefato de conhecimento, feito e refeito em contextos de intrincadas disputas, em arenas de contendas variadas, por meio de argumentos interessados (Scott 2013 , 2014). Um constructo, um conceito enredado em projetos e poéticas de transformação social.

A aposta na descontinuidade pode afetar outras epistemologias e cartografias do Caribe, pois oferece outros espaços de discussão, propicia novos exercícios comparativos que, simultaneamente, recusam a cartografia marcada pela repetição e a reificação da insularidade e da excepcionalidade (Dash 2003). Uma complexa e análoga cartografia instituiu as "Guianas" como imaginários-espaciais para estudos direcionados, respectivamente, à etnicidade, à criolização, ao pluralismo e uma gama de outros conceitos caros à literatura etnológica sobre as populações ameríndias e o seu arsenal conceitual. O Caribe Atlântico, e o seu duplo, o Amazônico, emergem como evidências do que poderíamos chamar "insularidades epistemológicas", pois cada qual parece resultar de investimentos contidos, isolados e autorreferentes, demarcando fronteiras e territorializando tradições antropológicas do Atlântico Norte (Trouillot 1992). Evitar o recorte localista que, a exemplo dos estudos sobre populações ameríndias nas terras baixas da Amazônia, impediu tanto os exercícios de comparação quanto reificou uma "imagem que se tornou típica na região": insularidade e diferença. Críticas à noção de "sociedade", à identificação de formas "atomistas" e "individualistas nas relações entre pessoas e grupos" no planalto guianense (Rivière et al. 2007: 253) poderiam ser tomadas como a versão da "excepcionalidade" de certas socialidades caribenhas (como problematizou J. M. Dash, para o caso do Haiti) em escala ampliada. Um Caribe amazônico, comprimido entre as margens dos rios, avesso à intensa circulação de gente, objetos e ideias, um movimento contínuo, mas conceitualmente diverso daquele que poeticamente Kamau Brathwaite nomeou tideletics. Inspirados em Glissant (1990), mas desconstruindo o conceito cunhado por Brathwaite por meio de trocadilhos para captar o movimento ribeirinho, em vez de "sea is history", poderíamos dizer que, como perspectiva da qual se pode compreender os movimentos e as presenças, os rios "see the histories". ${ }^{1}$

Essa ambiguidade deriva do reconhecimento de que, embora essas regiões sejam, reconhecidamente, palco de encontros e experimentações originais, os conceitos e as questões que as fazem emergir como objetos do conhecimento antropológico se afiguram apartados. Vale destacar, por exemplo, um amplo e diverso espaço sociocultural tradicionalmente conhecido em estudos e análises no campo etnológico, em particular aqueles dedicados às populações ribeirinhas e ameríndias; análises etno-históricas sobre as comunidades 
maroons localizadas nos atuais territórios do Suriname e da Guiana Francesa; os estudos sobre creolização, etnicidade, religiosidade e migração; e, finalmente, estudos sobre estratificação social, parentesco, família e comunidades rurais guianenses produzidos desde a década de 1950. O que essas diferentes agendas têm em comum é o mútuo desconhecimento e isolamento. Poderíamos dizer excludentes, na medida em que, explícita ou implicitamente, rejeitam a conexão dos problemas ou a validade da aplicação de certos conceitos, em parte devido aos pressupostos de singularidade dos grupos estudados. Ao contrário, suas agências, experiências, práticas de criação e apropriação de conhecimento sugerem que tais margens, fronteiras, contornos, semelhanças e diferenças no plano sociocultural e espaço-temporal - demarcadas de maneira específica pelo conhecimento antropológico - encontram-se em movimento e transformação. São circunstanciais.

Seguindo as pegadas de Trouillot, faz-se necessário rever criticamente a localização epistemológica e histórica de redes e vínculos institucionais, das trajetórias acadêmicas "geopolíticas" que criaram o Caribe como um artefato de conhecimento. Parafraseando Deborah Thomas e Karla Slocum (2008: 124-125), é urgente questionarmos a necessidade e a potencialidade da "generalização" de certos conceitos produzidos no e para entender o Caribe "em/para outras partes do mundo" e as "particularidades das experiências caribenhas e seus instrumentos conceituais”. Até que ponto generalização e particularismo engendram modos diversos de compreender processos sociais na região, sem que sejam concebidos como continuidade da tradição dos "estudos de área"? Se observarmos o modo pelo qual a tradição antropológica sobre o Caribe tornou-se objeto de inquirição crítica e ceticismo por uma pletora de escritores e intelectuais caribenhos, o que mais poderia ser dito ou conhecido em nome da disciplina? Seria ainda possível (ou mesmo, razoável) olvidar a proliferação de conceitos e alternativas analíticas que emergem de uma rica produção de textos acadêmicos e literários? Qual etnografia escaparia a essa quase captura?

Como alternativa para a reflexão e o exercício metodológico no tratamento de temas diversos, à alteração de rota e ao campo de visão vislumbrados por Michel-Rolph Trouillot no apagar do século passado, podemos debitar uma transformação no "campo" cujo alcance vem sendo objeto de importantes reflexões contemporâneas. Autores como David Scott (1999, 2013, 2014), Deborah Thomas e Karla Slocum (2008), Anthony Bogues (2002), Brian Meeks e Folke Lindahl (2001) permanecem explorando os arquivos e os "contra-arquivos" (Thomas 2016), os mapas e os "contrafetichismos" (Coronil 1993), inquirindo acerca da natureza do conhecimento antropológico sobre as socialidades caribenhas produzido por muitos de nós, no caso deste dossiê, antropólogas e antropólogos brasileiros e com formação acadêmica no Brasil, cujos olhares enviesados parecem confortavelmente protegidos por uma tensa 
fronteira já demarcada. "Desde longe”, “desde fora” e, por que não dizer, desde uma antropologia enredada por questões locais - aquelas que compõem uma agenda de estudos produzidos no Brasil. Qual antropologia das socialidades caribenhas, quando seus autores experimentam posicionar-se "fora" e críticos das tradições euro-americanas e suas ficções de singularidade e excepcionalidade caribenha? Pois é possível recusar o "Caribe" como um certo constructo ao percebermos que os sujeitos das experiências que até então seus autores pretenderam descrever não têm voz nos indexadores, nos eixos temáticos, nas cartografias e nas concepções que informam as epistemologias que tornaram-se objetos da disciplina. Além de reconhecer o caráter artefactual e construído de certas epistemologias que participaram da invenção do Caribe, não estariam as etnografias contemporâneas mais abertas à experimentação, tornando-se, de fato e de direito, algo artesanais? Por envolverem outros afetos, olhares contaminados por outras afinidades e compromissos, não estariam participando da (re)criação de outros artefatos de conhecimento?

Seria possível apostarmos em deslocamentos em diferentes direções e "centros de gravidade", criando condições e redes - sociotécnicas e políticas - afeitas a interlocuções, associações e agendas diversas; investir na produção de conhecimentos sobre as socialidades caribenhas articulados a um conjunto de conceitos e questões em estado bruto, afetos de novas criações. Conhecimentos que nos proporcionariam estabelecer relações de estranhamento e participação - o que não implica pertencimento - com distintas tradições antropológicas (Maurer 2002, 2004; Slocum e Thomas 2003, 2007). O papel da etnografia seria menos o do registro, da documentação, do arquivo, da confecção de evidências, mas o de captar a voltagem, o timbre e a frequência irradiada por outros modos de existência (Latour 2013). Etnografias sobre diferentes modos de criar e fazer uso de conhecimentos a partir de experiências que agenciam diferentes ontologias, histórias, atores, cosmologias. Trata-se de emular processos criativos de comunicação e expressão. Por este caminho, seria então possível etnografar - inventar um modo de falar e escrever sobre as coisas inventadas no curso da vida - com os nossos interlocutores fazendo uso das teorias e conceitos por eles criados. Uma alternativa para acedermos aos efeitos das práticas e das criações conceituais no presente-político (Scott 1991) dos nossos interlocutores, e não à gênese, de diferentes modalidades de transformação. Retomar a poética relacional de Edouard Glissant $(1997,1999)$ na leitura crítica de Sylvia Wynter (1989): recuperar nossa atenção para os caprichos da "relação" - não como síntese, mas virtualidade, forma e a trama do que designamos "o social" - afinal, o objeto de desejo da etnografia. Quando a "relação" emerge como o foco da nossa atenção etnográfica, ela altera sobremaneira o pano de fundo, o contexto e o horizonte que parecem preexistir ao evento e impedir o inusitado. Ela produz um recorte, abre espaço para múltiplas perspectivas, põe de ponta-cabeça o contínuo, o tropo da história feita de pedaços. 
Seja a partir de leituras críticas sobre a literatura sobre o Caribe, seja por causa da proximidade com a rica produção de estudos de etnologia sobre as socialidades guianenses, os autores que contribuem neste dossiê parecem concordar com as implicações e os desdobramentos da apartação, da insularidade, das epistemologias assentes no excepcionalismo. O Caribe que emerge do cruzamento de várias experiências de mobilização política e transgressão de fronteiras geopolíticas, nacionais e simbólicas é diverso de uma configuração jurídico-institucional que o concebe ora como exemplo histórico, resultado do cruzamento de formas de expansão colonial, ora como um objeto da inquirição antropológica. Vistas a partir dos fluxos de pessoas, objetos e cosmologias, as socialidades examinadas nos casos a seguir são outras coisas que apenas inscrições geopolíticas e fronteiras de solidariedade étnica. Essa premissa é informada pela apreensão de experiências similares analisadas em estudos de natureza histórica e etnográfica diversa.

Os artigos aqui reunidos resultam de um convite à reflexão acerca de dois conjuntos temáticos que fazem parte dos estudos antropológicos sobre o Caribe, mas que raramente aparecem associados. De um lado, seus autores debruçam-se sobre produção de miríades de "artefatos" - por vezes transmutados em mercadorias, conhecimentos, intervenções digitais, audiovisuais e artísticas, corpos, formas de materialização de agências espirituais e não humanas. De outro, o fazem reinscrevendo as relações, as redes e os trânsitos nos quais os artefatos e as pessoas se mostram enredados. Ou seja, investem naquilo que a literatura etnológica sobre as terras baixas amazônicas vem, nas últimas décadas, designando "regimes de transformação". Contudo, se, neste caso, trata-se de transformações ontológicas, anti-históricas ou não históricas - na medida em que recusam, invertem e desentendem a historicidade das formas de reprodução do social como teleológicas, lineares, e isomórficas, privilegiadas sob o colonialismo, a égide do Estado-nação ou do capitalismo -, no caso caribenho, essa oposição participa de e recria alguns dos elementos que as tornaram inteligíveis. Por esse caminho, antes de mostrarem-se mutuamente excludentes, "regimes de transformação" e "regimes de história" parecem conter virtualidades. As socialidades caribenhas e os modos pelos quais as pessoas que nelas vivem experienciam e traduzem a circulação incessante de coisas, pessoas e agências e, com elas, participam de novas relações, são, por esses caminhos, objetos de observação e criação múltiplos. Em vez de etapa de um "processo", histórias dos tempos coloniais ou do passado são apenas outros modos de habitar o presente. Nos artigos de Castro, Torres, Mello e Cunha essas virtualidades podem ser vistas por meio de minuciosas descrições de processos de transformação nos quais relações são transmutadas em conceitos; artefatos de conhecimento utilizados para descrever, aumentar, realçar ou traduzir novas relações.

Conceitos que circulam no espaço-tempo de comunidades, populações, famílias, migrantes, indocumentados que atravessaram fronteiras, circularam 
por territórios pouco conhecidos, "criolizaram" línguas e conhecimentos exógenos, foram submetidas a diferentes regimes de sujeição. As intervenções reunidas nesse dossiê procuram descrever, a partir de esforços etnográficos, os trânsitos complexos que vêm permitindo a objetificação de certos conceitos em contextos em constante mutação - pois já não traçam com prévias imagens de uma certa antropologia do Caribe uma relação de conforto e continuidade. Os artigos aqui reunidos propõem etnografar, por meio de aproximações comparativas, alguns efeitos de processos de transformação de artefatos - materiais e de conhecimento - a partir de experiências concretas e que mobilizam diferentes formas de criação.

\section{BIBLIOGRAFIA}

BOGUES, Anthony, 2002, "Politics, nation and postcolony: Caribbean inflections", Small Axe, 6 (1): 1-30.

CORONIL, Fernando, 1993, “Challenging colonial histories: Cuban counterpoint/Ortiz's counterfetishism”, em S. M. Bell, A.H. LeMay e L. Orr (orgs), Critical Theory, Cultural Politics, and the Latin American Narrative. South Bend, Notre Dame University Press, 61-80.

DASH, J. Michael, 2003, "Caraïbe fantôme: the play of difference in the francophone Caribbean”, Yale French Studies, 103: 93-105.

ENGELKE, Mattew, 2008, “The objects of evidence”, Journal of the Royal Anthropological Institute, 14: S1-S21.

FIELDS, Karen, 2001, "Witchcraft and racecraft: invisible ontology in its sensible manifestations”, em George C. Bond e Diane M. Ciekawy (orgs.), Witchcraft Dialogues. Athens, $\mathrm{OH}$, Ohio University Center for International Studies, 283-315.

GELL, Alfred, 1998, Art and Agency: An Anthropological Theory. Oxford, Clarendon Press.

GLISSANT, Edouard, 1990, Poétique de la relation. Paris, Gallimard.

GLISSANT, Edouard, 1997, Poetics of Relation. Ann Arbor, University of Michigan Press.

GLISSANT, Edouard, 1999, Caribbean Discourse. Charlottesville, University of Virginia Press.

HOLBRAAD, Martin, 2013, "How things can unsettle", em Penny Harvey et al. (orgs.), Objects and Materials: A Routledge Companion. Londres, Routledge, 228-237.

JOSEPHS, Kelly Baker, 2003, "Versions of x/self: Kamau Brathwaite’s Caribbean discourse”, Anthurium: A Caribbean Studies Journal, 1 (1): 4-15.

LATOUR, Bruno, 2005, Reassembling the Social: An Introduction to Actor-Network Theory. Oxford, Oxford University Press.

LATOUR, Bruno, 2013. An Inquiry into Modes of Existence. Cambridge, MA, Harvard University Press. 
MAURER, Bill, 2002. "Fact and fetish in creolization studies: Herskovits and the problem of induction, or, Guinea coast, 1593", New West Indian Guide, 76: 5.

MAURER, Bill, 2004, "Ungrounding knowledges offshore Caribbean studies, disciplinarity and critique", Comparative American Studies, 2 (3): 324-341.

MEEKS, Brian, e Folke LINDAHL (orgs.), 2001, New Caribbean Thought: A Reader. Mona, University of West Indies Press.

RIVIERE, Peter, et al., 2007, "A propósito de redes de relações nas Guianas". Mana, 13 (1): 251-273.

SCOTT, David, 1991, "That event, this memory: notes on the anthropology of African diasporas in the New World", Diaspora: Journal of Transnational Studies, 1 (3): 261-284.

SCOTT, David, 1999, Refashioning Futures: Criticism After Postcoloniality. Princeton, Princeton University Press.

SCOTT, David, 2013, "On the question of Caribbean studies", Small Axe: A Caribbean Journal of Criticism, 17 (2): 1-7.

SCOTT, David, 2014, "The temporality of generations: dialogue, tradition, criticism", New Literary History, 45 (2): 157-181.

SHELlER, Mimi, 2003, Consuming the Caribbean: from Arawaks to Zombies. Londres, Routledge.

SLOCUM, Karla, e Deborah A. THOMAS, 2003, "Rethinking global and area studies: insights from Caribbeanist anthropology", American Anthropologist, 105 (3): 553-565.

SLOCUM, Karla, e Deborah A. THOMAS, 2007, "Introduction: locality in today's global Caribbean: shifting economies of nation, race, and development", Identities: Global Studies in Culture and Power, 14 (1-2): 1-18.

STRATHERN, Marilyn, 1990, "Artefacts of history: events and the interpretation of images", em Jukka Siikala (org.), Culture and History in the Pacific. Helsínquia, The Finnish Anthropological Society, Transactions, 27: 24-44.

THOMAS, Deborah A., 2013, "Caribbean studies, archive building, and the problem of violence", Small Axe: A Caribbean Journal of Criticism, 17 (2): 27-42.

THOMAS, Deborah A., 2016, "Time and the otherwise: plantations, garrisons and being human in the Caribbean”, Anthropological Theory, 16 (2-3): 177-200.

THOMAS, Deborah A., e K. SLOCUM, 2008, "Caribbean studies, anthropology, and US academic realignments", Souls, 10 (2): 123-137.

TROUILlOT, M.R., 1983, "The production of spatial configurations: a Caribbean case", New West Indian Guide, 57: 215-229.

TROUILLOT, M.R., 1991, “Anthropology as metaphor: the savage's legacy and the postmodern world", em Richard Fox (org.), Recapturing Anthropology: Working in the Present. Santa Fe, School of American Research Press, 17-44.

TROUILLOT, Michel-Rolph, 1992, “The Caribbean region: An open frontier in anthropological theory", Annual Review of Anthropology, 21 (1): 19-42.

TROUILLOT, Michel-Rolph, 2002, "North Atlantic universals: analytical fictions, 1492-1945”, The South Atlantic Quarterly, 101 (4): 839-858.

TROUILLOT, Michel-Rolph, 2016, Global Transformations: Anthropology and the Modern World. Nova Iorque, Springer.

WYNTER, Sylvia, 1989, "Beyond the word of man: Glissant and the new discourse of the Antilles”, World Literature Today, 63 (4): 637-648. 